\title{
Role of Tamsulosin with or without Deflazacort to facilitate stone clearance after ESWL: a single-center randomized controlled study
}

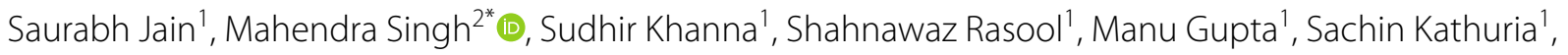
Amrendra Pathak ${ }^{1}$ and Himanshu Pandey ${ }^{2}$

\begin{abstract}
Background: Extracorporeal shock wave lithotripsy (ESWL) is the treatment of choice for upper tract calculi of moderate size. After ESWL, various factors affect the passage of small fragments through ureter like fragment's size and location. To facilitate fragment passage, a lot of medications have been tried and few have stood the test of the time. In this prospective study, we evaluated the role of Tamsulosin with or without Deflazacort versus no treatment after ESWL for ureteric and renal stones in terms of requirement of the number of ESWL sessions, stone clearance rate, stone expulsion time and analgesia requirements.
\end{abstract}

Results: Patients presenting between age-groups of 18-70 years with solitary renal/ureteric calculus of size between 6 and $15 \mathrm{~mm}$ in major axis with Hounsfield unit less than 1000 were recruited in one of the three groups (A, B and C) randomly. Patients in Group A were prescribed Tamsulosin (0.4 mg once daily) with Deflazacort (30 mg once daily), Group B were given Tamsulosin (0.4 mg once daily), and Group C received no treatment (analgesics SOS and hydration therapy) after undergoing ESWL. Two hundred and twenty-five patients were recruited in Group A, and 240 patients were recruited in Group B and Group $C$ each. There was an insignificant difference for required mean ESWL sessions and stone clearance rate between three groups. There was an early clearance of stone fragments in Group A than in Groups B and C, and it was statistically significant between Group A and Group C, specifically in the subgroup of stone size 10.1-15 mm. The requirement of mean analgesic tablets difference was significant between Groups A and C.

Conclusions: Tamsulosin with Deflazacort decreases the number of required ESWL sessions and improves complete stone clearance, but the difference is not significant. There were significant improvement in facilitating early stone clearance and decrease in requirement of mean analgesic tablets after ESWL with Tamsulosin and Deflazacort. Thus, Tamsulosin with Deflazacort can be used safely to facilitate stone clearance without increased complication rate.

Keywords: Tamsulosin, Deflazacort, ESWL, Analgesic, Urolithiasis

*Correspondence: dr.mahi1118@gmail.com

2 Room No 224, Department of Urology, AllMS, Jodhpur 342001, India Full list of author information is available at the end of the article

\section{Background}

Urolithiasis is the third most common disease of the urinary tract and one of the most common afflictions of modern society, affecting $4-15 \%$ of the world population [1]. Extracorporeal shock wave lithotripsy (ESWL) is used as the primary approach for renal stones smaller than $10 \mathrm{~mm}$ [2]. Once the calculus is fragmented with 
ESWL, various factors affect the passage of small fragments through ureter like fragment's size and location. It means at this stage the management is similar to medical management of ureteric calculi [3]. Tamsulosin with or without anti-edema agents such as corticosteroids is commonly used to treat patients with lower ureteric stones. However, only a few studies have defined the contribution of Tamsulosin and Deflazacort after ESWL for renal and upper ureteric stones $[2,4]$. In this prospective study, we evaluated the role of Tamsulosin with or without Deflazacort versus no treatment after ESWL for ureteric and renal stones in terms of stone clearance, expulsion time and analgesia requirements.

\section{Methods}

This prospective, randomized, open-label, comparative study was conducted from July 2015 to March 2018. Sample size calculation was done by $\mathrm{G}^{*}$ power (version 3.2.1, Germany). A previous study indicated a similar protocol; the rates of expulsion for the three groups were $84.8 \%$, $60 \%$ and $33.3 \%$ in Group A (Tamsulosin with Deflazacort), Group B (Tamsulosin alone) and Group C (Analgesics SOS), respectively [5]. Using a two-tailed alpha value (0.05) and a beta value (0.2), 80 observations per group (total 240) were considered sufficient to ensure statistical significance.

Patients presenting between age-groups of 18-70 years with solitary renal/ureteric calculus of size between 6 and $15 \mathrm{~mm}$ in major axis with Hounsfield unit less than 1000 were included in the study. Renal or ureteric calculus was first proved on plain X-ray kidney, ureter and bladder (KUB) and ultrasonography (USG) of the kidney and further confirmed with intravenous urogram or CT scan. Patients with diabetes mellitus, hypertension, morbid obesity, active urinary tract infection, uncorrected coagulopathy and pregnancy were excluded from the study. Patients with previous failed ESWL, history of urinary tract surgery or endoscopic treatment and history of concomitant treatment with alpha blockers, calcium channel blockers or steroids were also excluded.

After clearance from the ethical committee, we included patients in the study who fulfilled the inclusion and exclusion criteria. After informed consent, patients were recruited in one of the three groups (A, B and C) randomly with the help of computer-generated random number table. Patients in Group A were prescribed Tamsulosin (0.4 mg once daily) with Deflazacort (30 mg once daily), Group B were given Tamsulosin (0.4 mg once daily), and Group $C$ received no treatment (analgesics SOS and hydration therapy) after undergoing ESWL.

The initial evaluation included a detailed clinical history, blood and urine investigations including a complete hemogram, kidney function test, urine routine microscopy and urine culture sensitivity. Preoperative plain X-ray KUB and USG or excretory urography or CT scan was performed in all cases to document stone size, location and hydronephrosis. The ureter between the pelviureteral junction and the upper border of the sacroiliac joint was defined as the upper ureter. The stone size was defined as the maximal diameter.

ESWL was performed using the Electromagnetic Siemens Lithotripter (Siemens Modularis Variostar URO, USA) as an outpatient procedure. Five grams of eutectic mixture of Lidocaine and Prilocaine was applied on an approximately $30 \mathrm{~cm}^{2}$ skin area corresponding to the entry site of the shockwaves, $60 \mathrm{~min}$ before the procedure. A maximum of 2500 shocks were delivered for each session or until complete fragmentation of the stone had occurred as judged by fluoroscopy. Following each session, the patient was observed for $2 \mathrm{~h}$ in recovery. Repeat session of ESWL was performed after 10 days if inadequate fragmentation of the stone was observed.

Patients were evaluated every 10 days post-ESWL with plain radiography KUB/fluoroscopy and USG KUB. Patients were followed for maximum 60 days for stone clearance. If stone clearance would not occur within 60 days, he/she was excluded from the study. Under analgesia protocol, patients were prescribed tablet Aceclofenac $100 \mathrm{mg}$ with Drotaverine $80 \mathrm{mg}$ on SOS basis. If pain persisted, tablet Ketorolac $10 \mathrm{mg}$ was advised. Injection Diclofenac $50 \mathrm{mg}$ was given after the failure of both the above drugs. Patients were asked to maintain the diary of analgesic intake. In hydration therapy, patients were asked to drink at least 1 glass of water every hourly. In the end, we compared efficacy of all three groups in terms of stone clearance, expulsion time and analgesia requirements after ESWL.

\subsection{Statistical methods}

Statistical testing was conducted with the SPSS 20 software. Continuous variables were presented as mean \pm SD. Categorical variables were expressed as frequencies and percentages. The comparison of normally distributed continuous variables between the groups was performed using ANOVA, and further paired comparison was done using Tukey or Tamhane as appropriate. Nominal categorical data between the groups were compared using Chi-squared test or Fisher's exact test as appropriate. For all statistical tests, $\mathrm{p}$ value less than 0.05 was considered to indicate a significant difference.

\section{Results}

Patients were recruited in one of the three groups (A, B and C) randomly. Two hundred and twenty-five (225) patients were recruited in Group A, and 240 patients were recruited in Group B and Group C each. Demographic 
Table 1 Demographic data of patients

\begin{tabular}{llll}
\hline & Group A & Group B & Group C \\
\hline Number of patients & 225 & 240 & 240 \\
Mean age (in years) & $37.60 \pm 12.08$ & $37.83 \pm 11.31$ & $37.73 \pm 10.26$ \\
Gender (male/female) & $170 / 55$ & $190 / 50$ & $185 / 55$ \\
Side (right/left) & $125 / 100$ & $115 / 125$ & $135 / 105$ \\
Location kidney/ureter & $95 / 130$ & $110 / 130$ & $130 / 110$ \\
Mean Hounsfield unit & $770 \pm 40$ & $790 \pm 35$ & $767 \pm 33$ \\
Mean stone size (mm) & $9.7 \pm 1.89$ & $9.22 \pm 1.66$ & $9.79 \pm 1.87$ \\
Stone size 6-10 mm/10.1- & $150 / 75$ & $165 / 75$ & $170 / 70$ \\
$\quad$ 15 mm & & & \\
\hline
\end{tabular}

data of patients are presented in Table 1 . Overall mean age was $37.72 \pm 11.16$ years (range $18-65$ years). Overall, 160 females $(22.7 \%)$ and 545 males $(77.3 \%)$ were enrolled in the study with male-to-female ratio of 3.4:1. There was no statistically significant difference between the three groups according to gender and age. The side distribution in all three groups was also comparable $(P=0.664)$ with overall incidence of $330(46.8 \%)$ on the left side and 375 (53.2\%) on the right side. In Group A, 95 (42.2\%) of patients had stone in kidney and $130(57.8 \%)$ had in ureter. In Group B, 110 (45.8\%) patients had renal stone and $130(54.2 \%)$ had ureteric stone. One hundred and thirty [130 (54.2\%)] patients had renal stone and 110 (45.8\%) had ureteric stone in Group C. These three groups were statistically comparable $(P=0.494)$ according to the location of the stone.
The mean stone size in Group A was $9.7 \pm 1.89 \mathrm{~mm}$ (range $7-14 \mathrm{~mm}$ ), in Group B was $9.22 \pm 1.66 \mathrm{~mm}$ (range 6-12 mm), and in Group C was 9.79 \pm 1.87 (range 7-14 mm). No significant difference was observed between the three groups $(P=0.791)$. One hundred and fifty (150) patients in Group A (66.7\%), 165 patients in Group B (68.7\%) and 170 patients in Group C (70.8\%) had stone size $6 \mathrm{~mm}-10 \mathrm{~mm}$. Seventy-five (75) patients in Group A (33.3\%), 75 patients in Group B (31.3\%) and 70 patients in Group C (29.2\%) had stone size between $10.1 \mathrm{~mm}$ and $15 \mathrm{~mm}$ (Table 1). Mean Hounsfield unit for Group A, Group B and Group C was $770 \pm 40,790 \pm 35$ and $767 \pm 33$, respectively, with no statistically significant difference (Table 1).

In Group A, the mean number of required ESWL sessions was $1.78 \pm 0.99$, in Group B was $1.98 \pm 0.86$, and in Group C was $2.31 \pm 1.17$. Patients in Group A required a less number of mean ESWL sessions as compared to Group B and C, but there was a statistically insignificant difference between all groups $(P=0.060)$ (Table 2). Complete stone clearance was achieved in 220 patients (97.8\%) in Group A, 235 patients (97.9\%) in Group B and 215 patients (89.6\%) in Group C. Though complete stone clearance was better in Groups A and B compared to Group $C$, there was no statistically significant difference $(P=0.200)$ between three groups (Table 3$)$. In the subgroup of stone size $6-10 \mathrm{~mm}, 5$ patients $(2.1 \%)$ had incomplete clearance in only Group $C$ and difference was statistically insignificant $(P=0.392)$. In the subgroup of stone size $10.1-15 \mathrm{~mm}$ size, 5 patients $(2.2 \%)$ in Group A,

Table 2 Comparison of the number of ESWL sessions required

\begin{tabular}{|c|c|c|c|c|c|c|c|}
\hline \multirow[t]{2}{*}{ No. of sessions } & \multicolumn{2}{|l|}{ Group A } & \multicolumn{2}{|l|}{ Group B } & \multicolumn{2}{|l|}{ Group C } & \multirow[t]{2}{*}{$P$ value } \\
\hline & Frequency & $\%$ & Frequency & $\%$ & Frequency & $\%$ & \\
\hline 1 & 120 & 53.3 & 70 & 29.2 & 70 & 29.2 & \\
\hline 2 & 55 & 24.4 & 120 & 50.0 & 80 & 33.3 & \\
\hline 3 & 30 & 13.3 & 40 & 16.7 & 45 & 18.8 & \\
\hline 4 & 20 & 8.9 & 5 & 2.1 & 35 & 14.6 & \\
\hline 5 & 0 & 0 & 5 & 2.1 & 10 & 4.2 & \\
\hline Total & 225 & 100 & 240 & 100 & 240 & 100 & \\
\hline Mean $\pm S D$ & $1.78 \pm 0.997$ & & $1.98 \pm 0.863$ & & $2.31 \pm 1.170$ & & 0.060 \\
\hline
\end{tabular}

Table 3 Comparison of groups in terms of stone clearance

\begin{tabular}{|c|c|c|c|c|c|c|c|}
\hline \multirow[t]{2}{*}{ Stone clearance } & \multicolumn{2}{|l|}{ Group A } & \multicolumn{2}{|l|}{ Group B } & \multicolumn{2}{|l|}{ Group C } & \multirow[t]{2}{*}{$P$ value } \\
\hline & Frequency & $\%$ & Frequency & $\%$ & Frequency & $\%$ & \\
\hline Complete & 220 & 97.8 & 235 & 97.9 & 215 & 89.6 & 0.200 \\
\hline Incomplete & 5 & 2.2 & 5 & 2.1 & 25 & 10.4 & \\
\hline Total & 225 & 100 & 240 & 100 & 240 & 100 & \\
\hline
\end{tabular}


Table 4 Comparison of groups in terms of stone clearance according to stone size

\begin{tabular}{|c|c|c|c|c|c|c|c|}
\hline \multirow[t]{3}{*}{ Stone clearance } & \multirow{2}{*}{\multicolumn{2}{|c|}{$\frac{\text { Group A }}{\text { Stone size (in } \mathrm{mm} \text { ) }}$}} & \multirow{2}{*}{\multicolumn{2}{|c|}{$\begin{array}{l}\text { Group B } \\
\text { Stone size (in } \mathrm{mm})\end{array}$}} & \multirow{2}{*}{\multicolumn{2}{|c|}{$\frac{\text { Group C }}{\text { Stone size (in } \mathrm{mm} \text { ) }}$}} & \multirow[t]{3}{*}{$P$ value } \\
\hline & & & & & & & \\
\hline & $6-10$ & $10.1-15$ & $6-10$ & $10.1-15$ & $6-10$ & $10.1-15$ & \\
\hline Complete & 150 & 70 & 165 & 70 & 165 & 50 & For 6-10 mm (0.392) \\
\hline Incomplete & 0 & 5 & 0 & 5 & 5 & 20 & For $10.1-11 \mathrm{~mm}(0.143)$ \\
\hline
\end{tabular}

Table 5 Comparison of groups in terms of stone clearance time

\begin{tabular}{lllll}
\hline $\begin{array}{l}\text { Groups } \\
\text { time in days } \\
\text { (mean } \pm \text { SD) }\end{array}$ & $\begin{array}{l}\text { Clearance } \\
\text { group }\end{array}$ & $\begin{array}{l}\text { M value } \\
\text { difference }\end{array}$ & \\
\hline A & $17.5 \pm 9.91$ & B & -2.500 & 0.470 \\
& & C & -6.453 & 0.010 \\
B & $20.0 \pm 8.59$ & A & 2.500 & 0.470 \\
& & C & -3.953 & 0.158 \\
C & $23.95 \pm 11.78$ & A & 6.453 & 0.010 \\
& & B & 3.953 & 0.158 \\
\hline
\end{tabular}

5 patients $(2.1 \%)$ in Group B and 20 patients in Group C (8.3\%) had incomplete stone clearance, but the difference was statistically insignificant $(P=0.143)$ (Table 4$)$.

The mean stone clearance time in Group A was $17.5 \pm 9.9$ days, in Group B was $20.0 \pm 8.59$ days, and in Group $C$ was $23.95 \pm 11.78$ days. The mean stone clearance time was less in Group A than in Groups B and C and was statistically significant in Group A as compared to Group C $(P=0.010)$. Patients in Group B also had less mean stone clearance time compared to group $C$, but the difference was not statistically significant $(P=0.158)$ (Table 5$)$. In the subgroup analysis of stone size $6-10 \mathrm{~mm}$, the mean stone clearance time was $16.33 \pm 9.28$ days in Group A, $17.88 \pm 7.81$ days in Group B and $21.52 \pm 10.04$ days in Group C. The difference was insignificant between Group A, Group B and Group $C(P=0.066)$ in terms of mean stone clearance time of stone size $6-10 \mathrm{~mm}$ (Table 6). The subgroup of stone size $10.1 \mathrm{~mm}$ to $15 \mathrm{~mm}$ also had same result as main groups and had a significant difference in mean stone clearance time between Group A and Group $C(P=0.034)$. The mean stone clearance time was $20.0 \pm 11.09$ days in Group A, 25.0 \pm 8.55 days in Group B and $32.0 \pm 13.98$ days in Group C (Table 7).

Complications were divided according to ClavienDindo classifications. Grade 1 complication was seen in $15(6.7 \%)$ patients in Group A and in 20 (8.3\%) patients each in Groups B and C. Grade 2 complications were

Table 6 Subgroup $(6-10 \mathrm{~mm})$ analysis of stone clearance time

\begin{tabular}{|c|c|c|c|c|c|}
\hline Groups & $\begin{array}{l}\text { Number of patients } \\
\text { in subgroup }(6-10 \mathrm{~mm})\end{array}$ & $\begin{array}{l}\text { Clearance time in days } \\
\text { (mean } \pm \text { SD) }\end{array}$ & Comparative group & Mean difference & $P$ value \\
\hline \multirow[t]{2}{*}{ A } & 150 & $16.33 \pm 9.28$ & B & -1.545 & 0.779 \\
\hline & & & C & -5.182 & 0.066 \\
\hline \multirow[t]{2}{*}{$B$} & 165 & $17.88 \pm 7.81$ & $A$ & 1.545 & 0.779 \\
\hline & & & C & -3.636 & 0.240 \\
\hline \multirow[t]{2}{*}{ C } & 165 & $21.52 \pm 10.04$ & $A$ & 5.182 & 0.066 \\
\hline & & & $B$ & 3.636 & 0.240 \\
\hline
\end{tabular}

Table 7 Subgroup (10.1-15 $\mathrm{mm}$ ) analysis of stone clearance time

\begin{tabular}{llllrr}
\hline Groups & $\begin{array}{l}\text { Number of patients in subgroup } \\
(\mathbf{1 0 . 1 - 1 5} \mathbf{~ m m})\end{array}$ & $\begin{array}{l}\text { Clearance time in days } \\
(\mathbf{m} \text { ) SD) }\end{array}$ & Comparative group & Mean difference & $P$ value \\
\hline A & 70 & $20.00 \pm 11.09$ & B & -5.000 & 0.466 \\
& & & $C$ & -12.000 & 0.034 \\
B & 70 & $25.00 \pm 8.55$ & A & 5.000 & 0.466 \\
& & & $C$ & -7.000 & 0.292 \\
C & 50 & $32.00 \pm 13.98$ & A & 12.000 & 0.034 \\
& & & B & 7.000 & 0.292 \\
\hline
\end{tabular}


seen in 5 patients each in Group A (2.2\%) and in Group B (2.1\%). Grade 3 complications were occurred in 5 patients each in Groups A (2.2\%) and B (2.1\%) and in 25 patients in Group C (10.4\%). These were not statistically significant $(P=0.459)$. Overall, $11.1 \%$ complications occurred in Group A, $12.5 \%$ in Group C and $18.7 \%$ in Group C. In Group A, 5 patients (2.2\%) had steinstrasse, 5 patient $(2.2 \%)$ developed fever, 10 patients $(4.4 \%)$ had hematuria, and 5 patients $(2.2 \%)$ had severe pain. In Group B, 5 patients $(2.1 \%)$ had steinstrasse, 5 (2.1\%) had fever, $5(2.1 \%)$ had hematuria, and $15(6.2 \%)$ patients had severe pain. In Group C, 25 patients (10.4\%) developed steinstrasse, 5 patients (2.1\%) developed hematuria, and 15 patients $(6.2 \%)$ developed severe pain. Patients who required injectable analgesics were considered to have severe pain as a complication. Patients with gross hematuria were managed conservatively, and patients with fever were treated with intravenous antibiotics (Table 8).

The mean requirement of the number of analgesic tablets after ESWL was $2.00 \pm 1.40$ in Group A, $2.35 \pm 1.60$ in Group B and $2.43 \pm 1.87$ in Group C. The difference was statistically significant in Group A and Group C $(P=0.025)$. Though Group A required less mean numbers of tablets than Group B $(P=0.340)$, and Group B required less mean numbers of tablet than Group $C$ $(P=0.242)$, the difference was statistically insignificant (Table 9).

\section{Discussion}

ESWL is the treatment of choice for upper tract calculi of moderate size. Limitations of ESWL like poor clearance rate and more time to clearance with occasional complaint of steinstrasse are well known [6]. To facilitate fragment passage, a lot of medications have been tried and few have stood the test of the time. The $\alpha$-blockers can facilitate stone passage by reducing ureteral spasm. They also increase pressure proximal to the calculus and relax the ureter distal to the stone $[4,6]$. Deflazacort is a synthetic heterocyclic corticosteroid, oxazoline derivative of Prednisolone with high efficacy, strong antiinflammatory activity and good tolerability [7]. The average potency ratio of Deflazacort to Prednisolone
Table 9 Comparison of requirement of analgesic tablets

\begin{tabular}{lllll}
\hline Groups & $\begin{array}{l}\text { Number } \\
\text { of tablets } \\
\text { required } \\
\text { (mean } \pm \text { SD) }\end{array}$ & $\begin{array}{l}\text { Comparative } \\
\text { group }\end{array}$ & $\begin{array}{l}\text { Mean } \\
\text { difference }\end{array}$ & P value \\
\hline A & $2.00 \pm 1.40$ & B & -0.354 & 0.553 \\
& & C & -0.896 & 0.025 \\
B & $2.35 \pm 1.60$ & A & 0.354 & 0.553 \\
& & C & -0.542 & 0.242 \\
C & $2.43 \pm 1.87$ & A & 0.896 & 0.025 \\
& & B & 0.542 & 0.242 \\
\hline
\end{tabular}

is $0.69-0.89$, and $6 \mathrm{mg}$ of Deflazacort is having equivalent anti-inflammatory potency as $5 \mathrm{mg}$ of Prednisolone $[7,8]$. Deflazacort is having small suppressive effect on hypothalamic-pituitary-adrenal axis due to low lipid liposolubility, low risk of sodium retention and hypokalemia due to substantial lack of mineralocorticoid activity and lower interference with carbohydrate and calcium metabolism in comparison with older corticosteroids. Thus, Deflazacort at doses with equivalent anti-inflammatory efficacy to Prednisolone with less severe adverse effects makes it a good choice. Deflazacort shows high dosage flexibility, due to its wide therapeutic index with oral daily dosage ranging from 6 to $90 \mathrm{mg}$ depending on the nature and severity of specific disease [8]. Deflazacort is also used in Duchenne muscular dystrophy at a higher dose of $0.9 \mathrm{mg} / \mathrm{kg} /$ day to enhance strength by their effect on myoblast proliferation, myogenic repair, muscle proteolysis and immunosuppression [9]. Deflazacort in combination with Tamsulosin is used at a much lower dose of $30 \mathrm{mg} /$ day in stone disease to reduce inflammation and edema associated with stone with a lower risk of adverse effects. In this study, Tamsulosin with or without Deflazacort was used in post-ESWL period to check whether these expedite the stone expulsion $[6,7]$.

Various studies have been performed to evaluate the role of alpha blockers and steroid in renal or ureteric stone after ESWL $[5,10,11]$. Our study enrolled a large number of patients compared to previously done studies.

Table 8 Comparison of complications according to Clavien grading

\begin{tabular}{|c|c|c|c|c|c|c|c|}
\hline \multirow{2}{*}{$\begin{array}{l}\text { Clavien grading } \\
\text { of complications }\end{array}$} & \multicolumn{2}{|l|}{ Group A } & \multicolumn{2}{|l|}{ Group B } & \multicolumn{2}{|l|}{ Group C } & \multirow[t]{2}{*}{$P$ value } \\
\hline & Frequency & $\%$ & Frequency & $\%$ & Frequency & $\%$ & \\
\hline Grade 1 & 15 & 6.7 & 20 & 8.3 & 20 & 8.3 & 0.459 \\
\hline Grade 2 & 5 & 2.2 & 5 & 2.1 & 0 & 0 & \\
\hline Grade 3 & 5 & 2.2 & 5 & 2.1 & 25 & 10.4 & \\
\hline Grade 4-5 & 0 & 0 & 0 & 0 & 0 & 0 & \\
\hline Total & 25 & 11.1 & 40 & 12.5 & 45 & 18.7 & \\
\hline
\end{tabular}


We assessed all the relevant parameters including the number of ESWL sessions, stone clearance time, stone clearance rate, complications and analgesic requirement in a large number of population.

A total of 705 patients were enrolled in this study. Kidney stone disease is relatively uncommon before the age of 20, but the incidence rises rapidly and peaks from 40 to 60 years of age and then declines from 65 years of age and beyond [12]. Typically men are approximately two to three times more frequently affected than females [13]. In our study, there was no statistically significant difference between the groups according to age and gender and in terms of side of stone.

In our study, the mean stone size in the patients of Group A was $9.70 \pm 1.89 \mathrm{~mm}$, in Group B was $9.22 \pm 1.66 \mathrm{~mm}$, and in Group C was $9.79 \pm 1.86 \mathrm{~mm}$ with no significant difference. In a study by Qadri et al., the mean stone size in the patients of the Tamsulosin group was $1.12 \pm 0.31 \mathrm{~cm}$ as compared to $1.05 \pm 0.26 \mathrm{~cm}$ in the control group. The mean stone size was higher in this study as compared to our study because they included up to $20 \mathrm{~mm}$ calculus in their study as compared to $15 \mathrm{~mm}$ in our study [14].

\subsection{Number of ESWL sessions}

In our study, difference between Group A and Group C was borderline insignificant in terms of required mean number of ESWL sessions. There was an insignificant difference for required mean ESWL sessions between Groups A and B and between Groups B and C.

Singh et al. studied role of Tamsulosin in clearance of upper ureteral calculi after ESWL and found that the median value of required ESWL sessions is 1 in the Tamsulosin group and 2 in the control group and the difference was significant in two groups $(P=0.031)$ [15]. In a study done by Naja et al. [4], patients in the Tamsulosin group required the less number of ESWL sessions than the control group (mean 1.66 vs 2.16) and the difference between required ESWL sessions was significant $(P=.005)$ between two groups. So, Tamsulosin with Deflazacort with a higher clearance rate can prevent some patients to undergo further treatment with ESWL.

\subsection{Stone clearance rate}

In a study conducted on stone size $5-15 \mathrm{~mm}$ by Hassan Ismail Mohamed, stone free rate after 3 sessions of ESWL was $89 \%$ in the control group and $85 \%$ in the Tamsulosin group with no statistically significant difference $(P=0.34)$. He concluded that the use of Tamsulosin after ESWL did not improve success and stone free rates, but decreased the expulsion time [16]. Qadri et al. analyzed and observed that the overall stone clearance rate in the control and Tamsulosin groups was $80.0 \%$ and $96.7 \%$ with statistically significant difference $(P<0.004)$. They stratified the size of stone in three groups and concluded that stone clearance rate was statistically significant in stone group size of $1.1-1.5 \mathrm{~cm}(P<0.003)$ and $1.6-2.0 \mathrm{~cm}$ $(P<0.05)$, but was statistically insignificant in the subgroup of stone size $0.6-1.0 \mathrm{~cm}(P<0.21)$ [14]. We found that though stone clearance was better in Tamsulosin with or without the Deflazacort group, there was no statistically significant difference between the three groups.

\subsection{Stone clearance time}

Singh et al. [15] found that the mean expulsion time of stone was $26.78 \pm 11.96$ in the Tamsulosin group and $31.28 \pm 18.31$ days in the control group, but the difference was statistically insignificant $(P=0.138)$. Qadri et al. found the mean stone clearance time for $0.6-1.0 \mathrm{~cm}$ stone size was $2.16 \pm 0.96$ weeks in the Tamsulosin group and $2.82 \pm 1.16$ weeks in the control group $(P<0.0001)$. For stone size $1.1-1.5 \mathrm{~cm}$, mean stone clearance time was $4.39 \pm 0.98$ weeks in the Tamsulosin group and $5.75 \pm 1.16$ weeks in the control group $(P<0.002)$. In stone size $1.6-2.0 \mathrm{~cm}$, the mean stone clearance time was $6.25 \pm 0.95$ weeks and 8 weeks in the study and control group, respectively $(P<0.172)$ [14].

In our study, there was an early clearance of stone fragments in Group A than in Groups B and C, and it was statistically significant between Group A and Group C, specifically in the subgroup of stone size $10.1-15 \mathrm{~mm}$. So, Tamsulosin with Deflazacort can help by facilitating early clearance with decreased ESWL session.

\subsection{Complications}

In the study of Naja et al. [4], overall 11 patients developed steinstrasse, 2 in the Tamsulosin group and 9 in the control group. One patient in each group was successfully treated with conservative management. Similarly in the study of Singh et al., 8 patients in the Tamsulosin group and 13 patients in the control group developed steinstrasse, but the difference was insignificant $(P=0.167)$. All these patients had stones in the size of $11-15 \mathrm{~mm}$. In the Tamsulosin group, 6 patients were treated conservatively and 2 patients required ureteroscopic removal of stone (URS). Of 13 patients in the control group, 5 required auxiliary procedure (URS) [15].

Hassan Ismail Mohamed used the modified ClavienDindo system to classify the post-ESWL complications. Overall, there were 4 (3\%) grade 1 complications and 8 (6\%) grade 2 complications. In the control group, there were $8(12 \%)$ complications, 4 with severe ureteric colic with the requirement of hospitalization and auxiliary procedure and another 4 with progressive hydronephrosis with fever. In the Tamsulosin group, 4 (6\%) patients had fever with progressive hydronephrosis 
[16]. Bhagat et al. [11] concluded that Tamsulosin improved the outcome of steinstrasse.

In our study, the difference in complication rates and steinstrasse is clinically insignificant between groups. Overall, a total of 35 (5.0\%) patients developed steinstrasse and in all patients ureteroscopic removal of stones (URS) was done as an auxiliary procedure.

\subsection{Requirement of analgesics}

In a study by Singh et al. [15], Visual Analogue Scale pain score in the Tamsulosin group was $24.92 \pm 7.57$ and in the control group was $41.81 \pm 17.24$, and the difference was statistically significant $(P=0.00)$. Hassan Ismail Mohamed showed that the mean cumulative Diclofenac dose was $380 \mathrm{mg} /$ patient in the Tamsulosin group and $750 \mathrm{mg} /$ patient in the control group and the difference was statistically significant $(P=0.004)$ [16]. We compared the requirement of the mean number of analgesic tablets in our study and found that the difference was significant between Groups A and C. We conclude that the use of Tamsulosin with Deflazacort can reduce most distressing symptoms of colic and associated with the decrease in requirement of analgesics.

In a meta-analysis by Skolarikos et al. [17], the stone clearance time, pain score, steinstrasse formation and the need for auxiliary procedures were decreased with alpha blockers.

We conclude that Tamsulosin with Deflazacort decreases the number of required ESWL sessions and also improves complete stone clearance after ESWL. Tamsulosin with Deflazacort also facilitates early stone clearance after ESWL and also decreases stone clearance time. Steinstrasse formation incidence is less with both Tamsulosin with Deflazacort and Tamsulosin alone. Requirement of mean analgesic tablets after ESWL is also decreased by Tamsulosin with Deflazacort compared to no treatment group. Thus, Tamsulosin with Deflazacort can be used safely to facilitate stone clearance without increased complication rate.

\section{Abbreviations}

ESWL: extracorporeal shock wave lithotripsy; USG: ultrasonography; X-ray KUB: X-ray kidney, ureter and bladder; URS: ureteroscopic removal of stone.

\section{Acknowledgements}

Not applicable.

\section{Authors' contributions}

SJ prepared the manuscript and analyzed the data, MS helped with critical revision of manuscript for important intellectual contents, SK designed the study and also performed supervision, SR helped in manuscript preparation, MG and SacK helped with drafting of manuscript and also supervised, and AP and HP helped with literature search. All authors read and approved the final manuscript.
Funding

None.

\section{Availability of data and materials}

The datasets used and/or analyzed during the current study are available from the corresponding author on reasonable request.

\section{Competing interests}

The authors declare that they have no competing interests.

\section{Consent for publication}

Not applicable.

\section{Ethics approval and consent to participate}

This study was approved by the ethics committee of Sir Ganga Ram Hospital. Written informed consent was obtained from all participants.

\section{Ethics committee reference numbers}

$\mathrm{EC} / 07 / 15 / 848$

\section{Author details}

${ }^{1}$ Department of Urology, Sir Ganga Ram Hospital, New Delhi, India. ${ }^{2}$ Room No 224, Department of Urology, AllMS, Jodhpur 342001, India.

Received: 30 December 2019 Accepted: 15 January 2020

Published online: 10 February 2020

\section{References}

1. Stoller ML (2013) Urinary stone disease. In: McAninch JW, Lue TF (eds) Smith and Tanagho's general urology, 18th edn. Lange medical books/ McGraw- Hill, San Francisco, pp 249-279

2. Fan B, Yang D, Wang J, Che X, Li X, Wang L, Chen F, Wang T, Song X (2013) Can Tamsulosin facilitate expulsion of ureteral stones? A meta-analysis of randomized controlled trials. Int J Urol 20(8):818-830

3. Nuss GR, Rackley JD, Assimos DG (2005) Adjunctive therapy to promote stone passage. Rev Urol 7(2):67-74

4. Naja V, Agarwal MM, Mandal AK, Singh SK, Mavuduru R, Kumar $S$ et al (2008) Tamsulosin facilitates earlier clearance of stone fragments and reduces pain after shockwave lithotripsy for renal calculi: results from an open-label randomized study. Urology 72(5):1006-1011

5. Porpiglia F, Vaccino D, Billia M, Renard J, Cracco C, Ghignone G et al (2006) Corticosteroids and Tamsulosin in the medical expulsive therapy for symptomatic distal ureter stones: single drug or association. Eur Urol 50(2):339-344

6. Kupeli B, Irkilata L, Gurocak S, Tunc L, Kirac M, Karaoglan U et al (2004) Does Tamsulosin enhance lower ureteral stone clearance with or without shock wave lithotripsy? Urology 64(6):1111-1115

7. Nayak S, Acharjya B (2008) Deflazacort versus other glucocorticoids: a comparison. Indian J Dermatol 53(4):167-170

8. Parente L (2017) Deflazacort: therapeutic index, relative potency and equivalent doses versus other corticosteroids. BMC Pharmacol Toxicol 18(1):1

9. McAdam LC, Mayo AL, Alman BA et al (2012) The Canadian experience with long-term Deflazacort treatment in Duchenne muscular dystrophy. Acta Myol 31(1):16-20

10. Hollingsworth JM, Rogers MA, Kaufman SR, Bradford TJ, Saint S, Wei JT et al (2006) Medical therapy to facilitate urinary stone passage: a metaanalysis. Lancet 368(9542):1171-1179

11. Bhagat SK, Chacko NK, Kekre NS, Gopalakrishnan G, Antonisamy B, Devasia A (2007) Is there a role for Tamsulosin in shock wave lithotripsy for renal and ureteral calculi? J Urol 177(6):2185-2188

12. Romero V, Akpinar H, Assimos DG (2010) Kidney stones: a global picture of prevalence, incidence, and associated risk factors. Rev Urol 12:86-96

13. Scales $C D$, Curtis LH, Norris RD, Springhart WP, Sur RL, Schulman KA et al (2007) Changing gender prevalence of stone disease. J Urol 177(3):979-982

14. Qadri SS, El Khalid S, Mahmud SM (2014) Effects and outcome of Tamsulosin more than just stone clearance after Extracorporeal Shock Wave Lithotripsy for renal calculi. J Pak Med Assoc 64:644-648 
15. Singh SK, Pawar DS, Griwan MS, Indora JM, Sharma S (2011) Role of Tamsulosin in clearance of upper ureteral calculi after extracorporeal shock wave lithotripsy. Urol J 8:14-20

16. Mohamed HI (2013) The efficacy of Tamsulosin therapy after Extracorporeal Shock-wave Lithotripsy for ureteric calculi: a prospective randomised, controlled study. Arab J Urol 11(4):398-404

17. Skolarikos A, Grivas N, Kallidonis P, Mourmouris P, Rountos T, Fiamegos A (2015) The efficacy of medical expulsive therapy (MET) in improving stone-free Rate and stone expulsion time, after extracorporeal shock wave lithotripsy (SWL) for upper urinary stones: a systematic review and meta-analysis. Urology 86:1057-1064

\section{Publisher's Note}

Springer Nature remains neutral with regard to jurisdictional claims in published maps and institutional affiliations.

\section{Submit your manuscript to a SpringerOpen ${ }^{\circ}$ journal and benefit from:}

- Convenient online submission

- Rigorous peer review

- Open access: articles freely available online

- High visibility within the field

- Retaining the copyright to your article

Submit your next manuscript at $\boldsymbol{\nabla}$ springeropen.com 